\title{
Feasibility of Usage of Thermoelectric Modules for Recovering of Low-Potential Heat from a Surface of Power Transformers
}

\author{
Roman Olekshii (Technician, AS Latvenergo), Nikolajs Kukḷa (Engineer, Latvian Electricity Network), \\ Ol̦egs Linkevičs (Associate Engineer, Riga Technical University)
}

\begin{abstract}
This paper analyses the possibility of using the lowpotential heat from a surface of power transformers. The authors discuss the production of electricity by means of thermoelectric modules.

The feasibility of usage of thermoelectric modules was analyzed by carrying out theoretical calculations and a series of experimental test, which gave a clear view of capability of an application of thermoelectric modules for recovering of lowpotential heat of power transformers.
\end{abstract}

Keywords - Low-potential heat, power transformers thermoelectric modules.

\section{INTRODUCTION}

Loses of high voltage power transformers, with nominal power rating higher than 125 MVA usually are less than $1 \%$ of nominal power. Still, it means that hundreds of $\mathrm{kW}$ is used useless for heating an atmosphere [1]. The European Union is planning to achieve $20 \%$ growth in energy efficiency by 2020 and $30 \%$ by 2030 . Energy prices are rising every year. Renewable energy is expensive and its control is limited. Fossil fuels are harmful for the environment that is why its usage for energy production shall be limited. Energy efficiency becomes a cost effective and interesting option for investors. Power transformers are good sources of waste heat, which can be recovered and easily controlled. An oil temperature of 250 MVA power transformer of Riga CHPP-2 at full load condition is shown at the diagram in Fig.1. We can see that at ambient temperature of $0^{\circ} \mathrm{C}$ top oil temperature reaches $40^{\circ} \mathrm{C}$. That means it could be used effectively by heat pumps to produce hot water for heating. However, power transformers do not operate at full load all the time and also can be shut down. That means there is a need to have alternative low potential heat source for heat pumps or alternative heating system. [2]

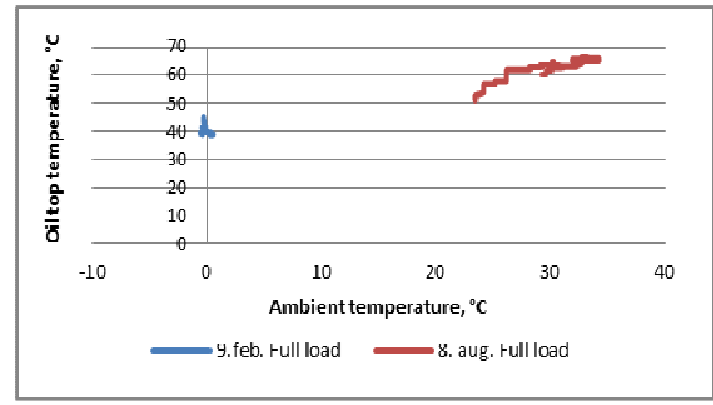

Fig. 1. 250 MVA power transformer oil top temperatures.
There is a possibility to apply thermoelectric modules to generate electricity using waste heat from a surface of power transformer. Generated electricity could be supplied to substation DC circuits, to provide power to measuring and protective devices and other applications. As substations already have rectifiers to provide DC, it means thermoelectric modules could be used as auxiliary source of power. So it is important to find out if thermoelectric module usage is possible in such way and how much power could be generated.

\section{THERMOELECTRIC MODULES}

Thermoelectric module is a semiconductor device, which is designed primarily for cooling or combined cooling and heating applications where electrical power creates a temperature difference across the module. If temperature difference exists between the cold and hot side of a module, it is possible to generate electrical power. [3]

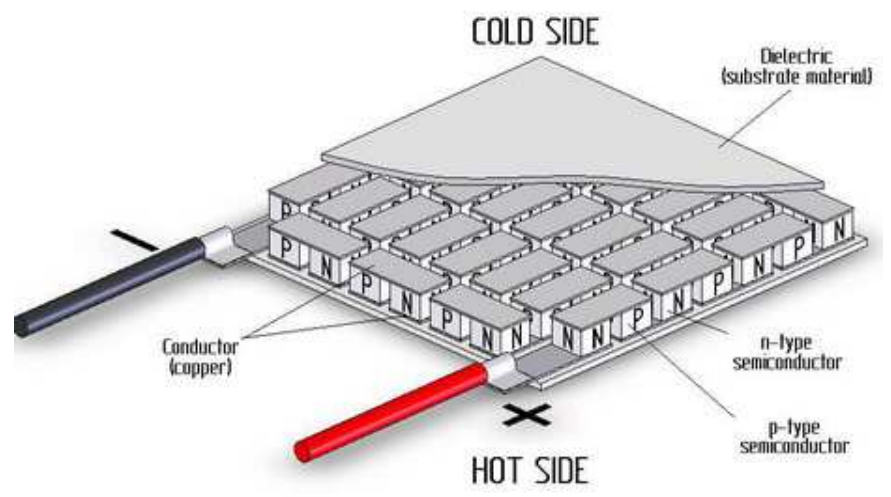

Fig. 2. Design of thermoelectric module [3].

Constructively thermoelectric modules are comprised from two or several p-type and n-type semiconductor materials, which electrically are connected in series and thermally are connected in parallel (see Fig. 2).

Thermoelectric modules are generally sandwiched between two ceramic plates, which are kept together and isolating the thermoelectric modules from each other and from surrounding environment. [3]

Heating of one side of a thermoelectric module and cooling the other side results in heat flow in a semiconductor material. As the heat flows from hot to cold, free charge carriers (electrons or holes) in the material are also driven to the cold 
side of the module. Thanks to these movements of charges, a potential difference between the module contacts is achieved. [4]

Electricity output from thermoelectric module depends greatly on the temperature difference between the cold and hot side of a module: the greater is the temperature difference, the grater is the movement of free charge carriers and the higher is electricity production of a module. It also depends on the surface temperature of a module: the higher is the surface temperature, the better are working conditions of a thermoelectric module. For modern thermoelectric modules the second condition (surface temperature) is less important than the first one (temperature difference).

The higher efficiency of thermoelectric modules for production of electricity is achieved, when the surface temperature is $150^{\circ} \mathrm{C}$ or above and the temperature difference is more than $100^{\circ} \mathrm{C}$. Main function of thermoelectric modules called Peltier coolers is to cool down or heat up the surface of any objects by using electricity. But Peltier coolers could be used in opposite way to recover a low-potential heat from a surface of any objects to produce electricity. Information about their generating ability could be found in [4].

The temperature of transformer surface is usually lower than needed for thermoelectric generators, it is about $30-55^{\circ} \mathrm{C}$ (see Fig.3.). Parameters of power transformer (shown in Fig.3) are described in table 1 . Nevertheless, the authors considered installation of Peltier modules on a surface of power transformer to feed different protection and measurement devices of transformer or other substation applications. Similar experiments were performed by K. Murakami [5].

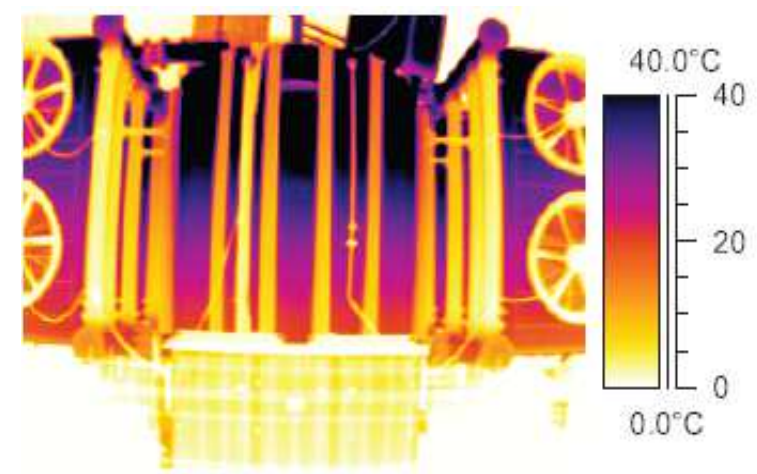

Fig. 3. 250 MVA power transformer thermovision at $90 \%$, ambient temperature $0^{\circ} \mathrm{C}$

K. Murakami in his study used different kinds of aluminum fins to cool down cold side of thermoelectric module. In his experiment he used $6.27 \times 6.27 \mathrm{~cm}$ thermoelectric module. The result he reached is shown in the diagram of Fig.4. We can see that at the surface temperature of $330^{\circ} \mathrm{K}$ ( or $56.85^{\circ} \mathrm{C}$ ), voltage of thermoelectric module reaches about $100 \mathrm{~mW}$. The author mentioned that when the surface temperature of heat source was $79.85^{\circ} \mathrm{C}$ and surrounding temperature was $24.85^{\circ} \mathrm{C}$, he gained temperature difference between hot and cold side of thermoelectric module equal to $36.5^{\circ} \mathrm{C}$. The mentioned temperature of heat source is very high. As it could be seen from Fig.3, a top temperature of transformers surface is $40{ }^{\circ} \mathrm{C}$. [6]

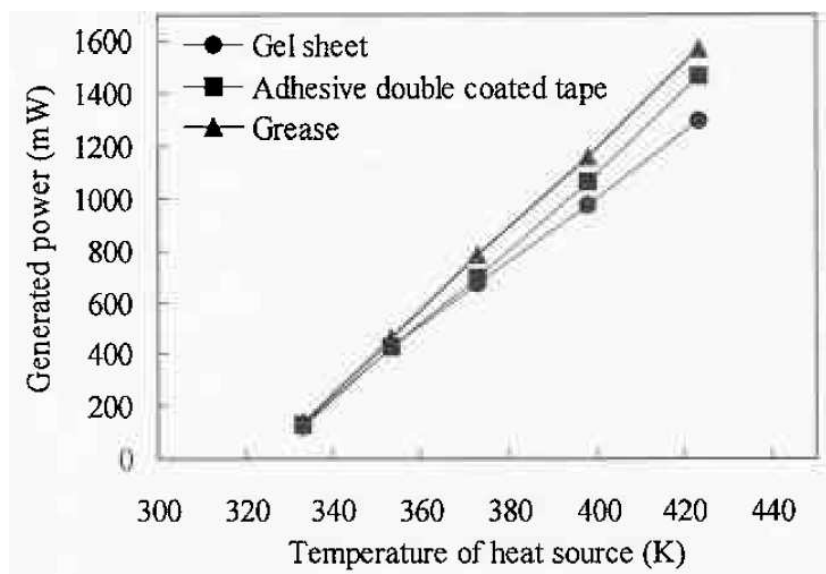

Fig. 4.K. Murakami experiment results [5].

During the hot summer day when ambient temperature reaches $26^{\circ} \mathrm{C}$, at full load (see Fig.1) transformers top oil temperature rises up to $68^{\circ} \mathrm{C}$. Still difference between ambient temperature and transformer does not exceed $42^{\circ} \mathrm{C}$. Which means that additional study should be made to find out if we can reach generated power from thermoelectric module similar to K Murakami results.

\section{THEORETICAL CALCULATIONS}

Theoretically, power and voltage produced by a module could be calculated if we know inner resistance of the module, material Seebeck coefficient and temperature difference between hot and cold side of the module. Seebeck coefficient shows the magnitude of an induced voltage in response to temperature difference across the material. This coefficient is different for all materials, also it depends on temperature. At higher operating temperatures better effect could be reached. [6]

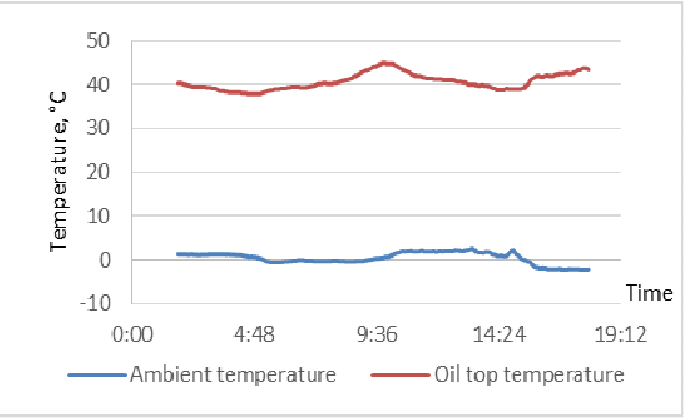

Fig. 5. 250 MVA power transformer oil top temperatures.

We found out that at $0^{\circ} \mathrm{C}$ ambient temperature 250 MVA power transformer surface temperature can reach about $40^{\circ} \mathrm{C}$ on top part of the transformer and $30^{\circ} \mathrm{C}$ in the middle part of transformer (see Fig. 3.). We will not use bottom part of transformer to mount thermoelectric modules, as it is seen from Fig. 3 the temperature is only about $20^{\circ} \mathrm{C}$, we already know that efficiency of thermoelectric module depends on surface temperature. To make calculation we need to know temperature difference between hot and cold side of thermoelectric module. In the diagram of Fig.5 we can see that 
temperature difference between top oil temperature, which mostly equal to transformer surface temperature, is $40^{\circ} \mathrm{C}$. It is clear, that we could not reach the same temperature difference between hot and cold side of thermoelectric module. We suggested it could be $30^{\circ} \mathrm{C}$.

All the data for theoretical calculation was taken from Ferotec manufacture webpage. The material of thermoelectric module is Bismuth Telluride. All the information for calculation of main parameters for 127 couple $4 \times 4 \mathrm{~cm}$ modules was provided. Main input data is: $\Delta \mathrm{T}=30^{\circ} \mathrm{C}, \mathrm{S}_{\mathrm{M}}=$ $0,05343 \mathrm{~V} /{ }^{\circ} \mathrm{C}, \mathrm{R}_{\mathrm{M}}=2,4796 \Omega$, where $\mathrm{S}_{\mathrm{M}}$ average Seebeck coefficient for module, $\mathrm{R}_{\mathrm{M}}$ average resistance of module.[3]

$$
U_{0}=S_{M} \times \Delta t=I \times\left(R_{M}+R_{S}\right)
$$

where $\mathrm{U}_{0}-$ obtained voltage from one module, $\mathrm{V}$;

$\mathrm{S}_{\mathrm{M}}-$ Seebeck coefficient, $\mathrm{V} /{ }^{\circ} \mathrm{C}$;

$\Delta \mathrm{t}$ - temperature difference between cold and hot side of module, ${ }^{\circ} \mathrm{C}$;

$\mathrm{I}$ - current, A;

$\mathrm{R}_{\mathrm{M}}$ - inner resistance of module, $\Omega$;

$\mathrm{R}_{\mathrm{S}}$ - resistance of load, $\Omega$.

In formula (1) we input $S_{\mathrm{m}}$ and $\Delta \mathrm{T}$ :

$$
U_{0}=0.05343 \times 30=1.6029 \mathrm{~V}
$$

Maximum power could be produced by one module:

$$
P_{\max }=\frac{U_{0}^{2}}{4 \times R_{M}}=\frac{1.6029^{2}}{4 \times 2.4796}=0.259 \mathrm{~W}
$$

where Pmax - maximal power of one module, $\mathrm{W}$.

We can calculate power that could be obtained from one transformer surface if we know dimensions of this power transformer. As an example power transformer "Areva" at Riga CHPP-2 has been taken, the main information about this transformer is available in table 1.

Power transformers height is $3.67 \mathrm{~m}$, length $8.46 \mathrm{~m}$, width 3 $\mathrm{m}$, dimensions were taken from power transformers documentation. Area of one 127 couple thermoelectric module is $16 \mathrm{~cm}^{2}$, or $0.0016 \mathrm{~m}^{2}$. Now area of transformer could be easily calculated. Modules would not be mounted on the top and on the bottom of the power transformer due constructive features. Also for calculation we will use only top and middle part of transformer.

TABLE I

PARAMETERS OF POWER TRANSFORMER

\begin{tabular}{|l|ll}
\cline { 1 - 2 } Areva 250 000/330/110 & \multicolumn{2}{l}{} \\
\cline { 1 - 2 } Nominal power & 250 & MVA \\
\hline Upper voltage & 330 & $\mathrm{kV}$ \\
\cline { 1 - 2 } Low voltage 1 & 115 & $\mathrm{kV}$ \\
\hline Low voltage 2 & 11 & $\mathrm{kV}$ \\
\hline Non load loss & 80 & $\mathrm{~kW}$ \\
\hline Load loss & 450 & $\mathrm{kkW}$ \\
\hline Cooling method & & ONAF \\
\hline
\end{tabular}

$$
A_{\text {s.l. }}=L_{1} \times h \times 2 \times k=8.46 \times 3.67 \times 2 \times 0.6=37.25 m^{2}
$$

where $\mathrm{A}_{\mathrm{s} . \mathrm{l}}$ - area for longest side, $\mathrm{m}^{2}$;

$\mathrm{L}_{1}$ - transformer length , m;

$\mathrm{h}$ - transformer height, $\mathrm{m}$;

$\mathrm{k}$ - coefficient that consider constructive features of transformer surface.

In the same way is calculated area for shorter sides of transformer:

$$
A_{\text {s.s. }}=L_{1} \times h \times 2 \times k=3 \times 3.67 \times 2 \times 0.6=13.21 \mathrm{~m}^{2}
$$

where $\mathrm{A}_{\text {s.l. }}-$ area for longest side, $\mathrm{m}^{2}$;

$\mathrm{W}_{1}$ - transformer width , $\mathrm{m}$;

$\mathrm{h}$ - transformer height, $\mathrm{m}$;

$\mathrm{k}$ - coefficient that consider constructive features of transformer surface.

The whole area available for modules is calculated:

$$
A=A_{\text {s.l. }}+A_{\text {s.s. }}=37.25+13.21=50.46 \mathrm{~m}^{2}
$$

where A - whole area of transformer surface used for thermoelectric modules, $\mathrm{m}^{2}$.

$A_{\text {s.s }}$ - area for short sides of transformer, $\mathrm{m}^{2}$

We mentioned, that we will use only top and middle part of transformer, so useful areal will 2/3 from whole area:

$$
A_{U}=2 / 3 \times A=2 / 3 * 50.46=33.64 m^{2}
$$

where $A_{U}$ - used area of transformer, $\mathrm{m}^{2}$.

Now we can calculate how many thermoelectric modules can be mounted on this transformer surface:

$$
n=\frac{A}{A_{\text {mod. }}}=\frac{33.64}{0.0016}=21025
$$

where $\mathrm{n}$ - quantity of thermoelectric modules;

$\mathrm{A}_{\text {mod. }}$ - area of one module, $\mathrm{m}^{2}$.

It means the total produced power by one transformer could reach:

$$
P_{\text {full }}=n \times P_{\max }=21025 \times 0.259=5445.48 \mathrm{~W}
$$

where $\mathrm{P}_{\text {full }}$ - maximal power could be generated by this amount of modules, W.

\section{EXPERIMENTAL MODEL}

It is hard to find low potential heat at temperature of 100$150^{\circ} \mathrm{C}$, especially if modules are mounted on transformers surface. So it is more common to know efficiency of thermoelectric modules at low heat source temperatures at about $40-60^{\circ} \mathrm{C}$. To analyze a behavior of thermoelectric modules if temperatures of $40-60^{\circ} \mathrm{C}$ are applied to hot side of the module, an experimental model shown in Fig. 6 was used. Experiments were performed with natural convection cooling.

It was not possible to purchase Ferrotec thermoelectric module so following thermoelectric modules were chosen for experiment series: TEC1-12703S, TES1-12703S, ET-131-1013-S-RS. Where TEC1-12703S is similar to Ferrotec theoretically studied module, it has the same dimensions and same amount of thermocouples. Main parameters of these 
modules could be seen in table 2 and picture in Fig.7. As they are not mentioned to be used as generating modules, there is no information about their generating ability.

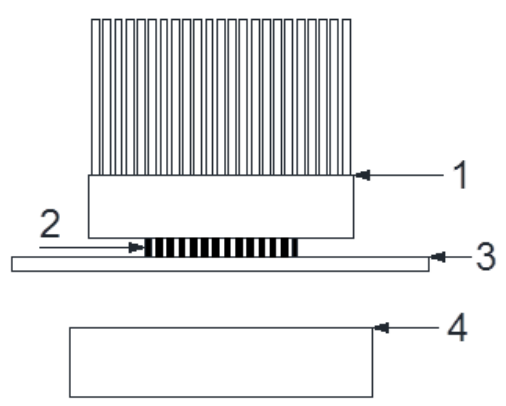

Fig. 6. Experimental model: 1 - additional cooling fin (only for experiments with additional cooler), 2 - thermoelectric module; 3 - heated surface; 4 heat source.

TABLE II

PARAMETERS OF THERMOELECTRIC MODULES

\begin{tabular}{|l|c|c|c|}
\hline Name & TEC1-12703S & TES1-12703S & $\begin{array}{c}\text { ET-131-10-13-S- } \\
\text { RS }\end{array}$ \\
\hline Designation & $\bmod 1$ & $\bmod 5$ & $\bmod 6$ \\
\hline Dimensions, $\mathrm{mm}$ & $40 \times 40 \times 3.6$ & $30 \times 30 \times 3.3$ & $40 \times 23 \times 3,$. \\
\hline
\end{tabular}

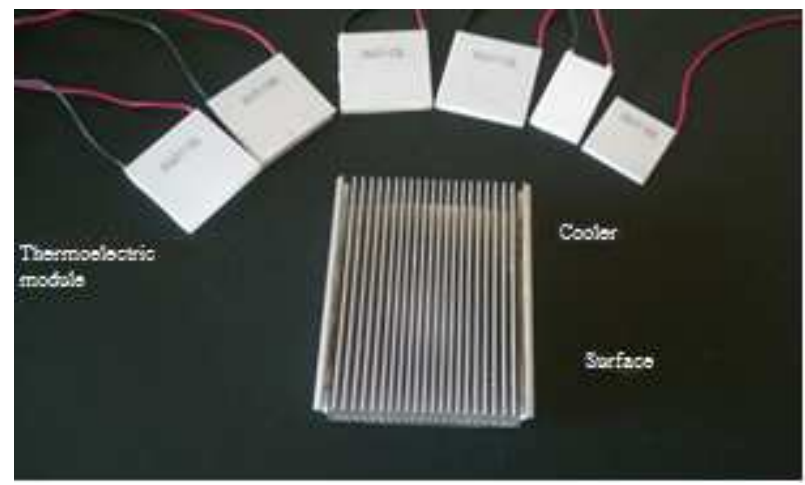

Fig. 7. Thermoelectric modules and cooler.

\section{RESULTS OF EXPERIMENTAL ACTIVITY}

The main aim of experiment series is to find out Peltier module generating ability at real power transformer temperature regimes. However, sun and wind influence were not taken into account. This allows to keep same conditions for all experiment series. Which means different thermoelectric modules could be compared.

First of all let us take the voltage of different thermoelectric modules for comparison (see Fig.8.), as it is one of the main parameters for thermoelectric generator. This experiment took place at ambient temperature of $15^{\circ} \mathrm{C}$ and surface temperature, where modules were mounted, was $50^{\circ} \mathrm{C}$. At first measurement point after $30 \mathrm{~s}$ of work the temperature difference between module hot and cold side is highest, so we got $196 \mathrm{mV}$ for TEC1-12703S, which is for 24\% lower than in theoretical calculation. But module heating process stopped only after $300 \mathrm{~s}$, and the voltage in stabile mode is $125 \mathrm{mV}$ for first module, and even lower for other two modules.

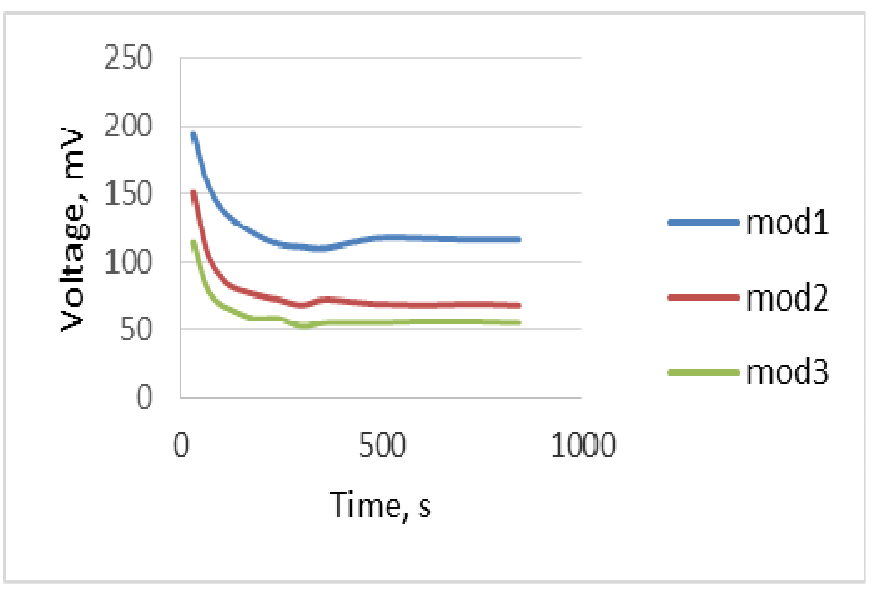

Fig. 8. Voltage of thermoelectric modules mod1- TEC1-12703S; mod2- ET131-10-13-S-RS; mod3- TES1-12703S.

Then a series of experiments were made for each module with surface temperature of $40^{\circ} \mathrm{C}$ and $60^{\circ} \mathrm{C}$. Ambient temperature was the same- $15^{\circ} \mathrm{C}$. Results of temperature measurements are seen in Fig.9.

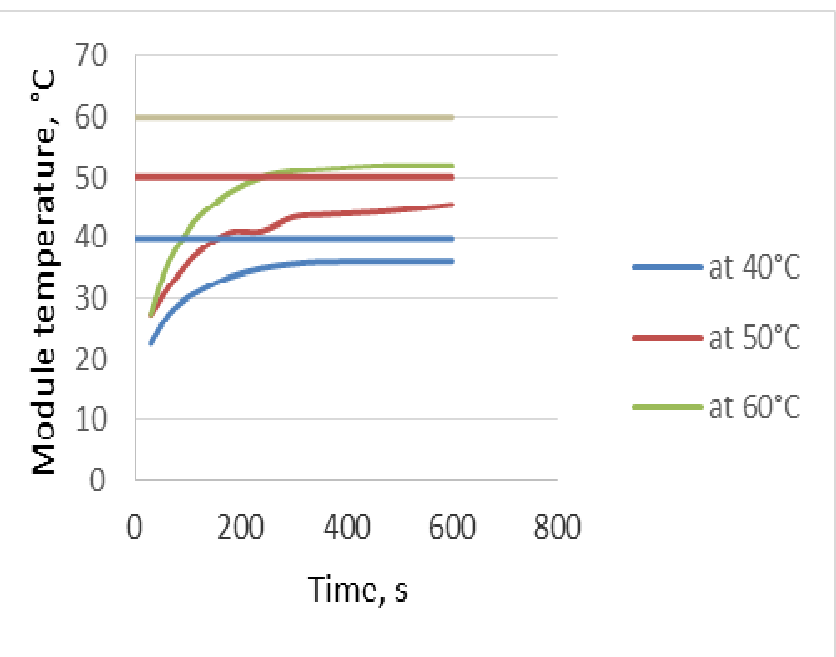

Fig. 9. Surface and cold side temperature of a module TEC1-12703S.

We can see that at the higher surface temperature difference between module hot and cold side temperatures is bigger. At surface temperature of $40^{\circ} \mathrm{C}$ difference between TEC-12703S module sides is only $3.8^{\circ} \mathrm{C}$, at $50^{\circ} \mathrm{C}$ difference is $5^{\circ} \mathrm{C}$, but at $60^{\circ} \mathrm{C}$ about $8^{\circ}$. It is clear now, that theoretically chosen temperature difference between hot and cold side of module was very optimistic and applies only for first moments after mounting module to hot surface.

In the diagram of Fig.10 we can see that highest voltage is gained with surface temperature of $60^{\circ} \mathrm{C}$ and it is for about 50 $\mathrm{mV}$ higher then were gained at surface temperature of $50^{\circ} \mathrm{C}$. But if we compare results at surface temperature of $40^{\circ} \mathrm{C}$ and $50^{\circ} \mathrm{C}$, we can see that voltage difference is lower, only $30 \mathrm{mV}$. Rise of surface temperature leads to higher thermoelectric module voltage. Rising temperature of power transformer case is possible, but it means worse working conditions for transformer insulation, that will lead to maintenance cost rise and it can negatively impress power transformer operating life time. 


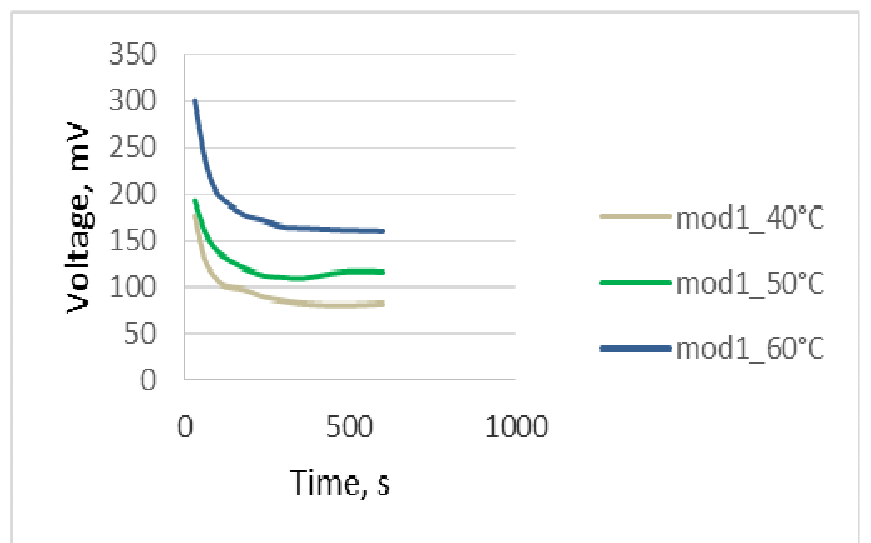

Fig. 10. Voltage of TEC1-12703S module as a function of surface temperature.

Other possibility to raise thermoelectric module productivity in generating mode is to gain bigger temperature difference between hot and cold side. In case when additional cooler is mounted on thermoelectric module cold side $10^{\circ} \mathrm{C}$ difference between module sides could be obtained at surface temperature of $50^{\circ} \mathrm{C}$. We did not use in our study forced air flow through cooler, because fans consume electricity.

From the diagram in Fig.11 we can see, that experiment took much longer time, because additional cooler significantly increases time needed to obtain stabile heat flow through thermoelectric module. Thermoelectric modules produced voltage at surface temperature of $50{ }^{\circ} \mathrm{C}$ is higher than before. Additional cooler was the same for each module. So rise in produced voltage from smaller modules was even higher than for bigger one TEC1-12703S. Produced voltage of TEC1$12703 \mathrm{~S}$ raised from $116 \mathrm{mV}$ to $226 \mathrm{mV}$, for ET-131-10-13-SRS from $68 \mathrm{mV}$ to $258 \mathrm{mV}$ and for TES1-12703S from $56 \mathrm{mV}$ to $178 \mathrm{mV}$. As last experiment took longer time the current also was measured. So we can calculate power produced by each module.

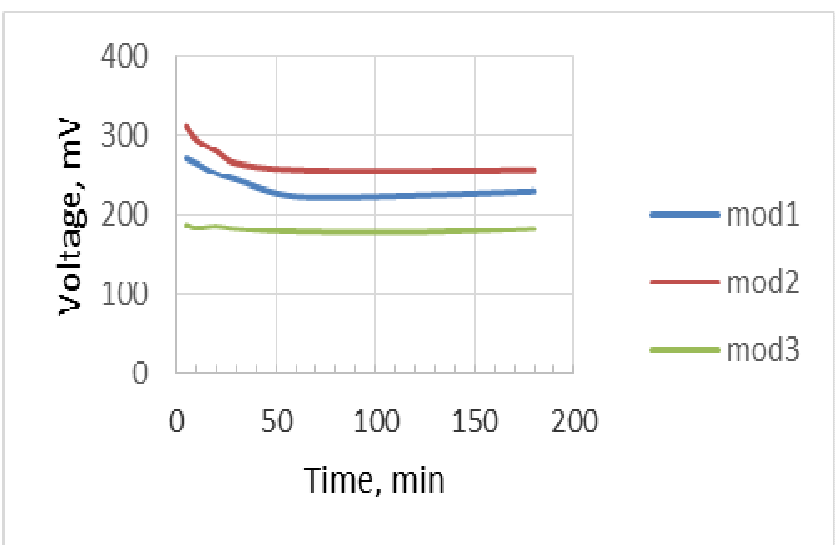

Fig. 11. Voltage of thermoelectric modules in case with additional cooler.

From Fig.11 we can see that module produced power is insignificant. To produce $1 \mathrm{~W}$ at least 273 ET-131-10-13-S-RS modules should be used. Each module price is about 10 EUR depending on purchased amount. That means very high costs for such system, with very low potential. The gained power could be higher if more qualitative thermoelectric modules are used. Of course the cost of each module will be higher. That means that overall costs could be even higher, but costs for 1 $\mathrm{W}$ could stay at about same level. Second opportunity to raise efficiency of thermoelectric modules is to use them in places where higher surface temperature is available. In this case more qualitative modules could show better efficiency. Also improving cooling circumstances could lead to result improvement, but additional costs and problems related with cooler mounting should be took into account.

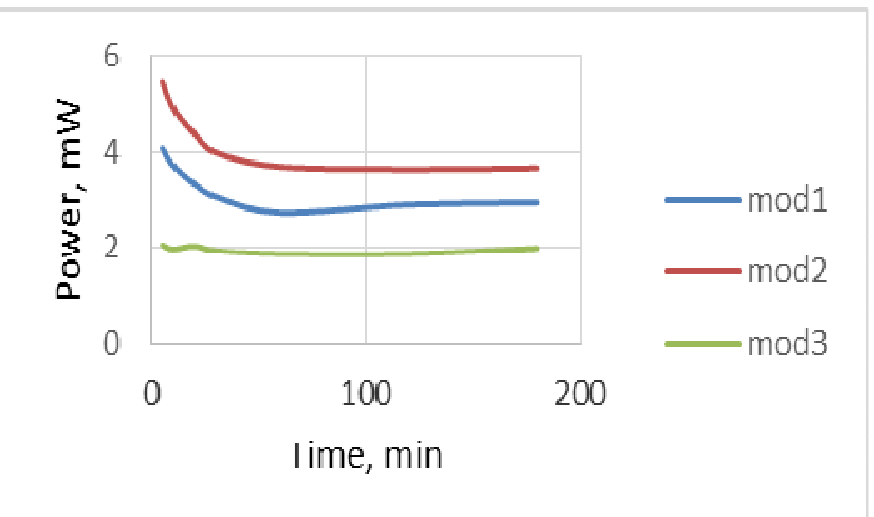

Fig. 12. Power of thermoelectric module in case when additional cooler is used, surface temperature is $50^{\circ} \mathrm{C}$.

Experiment, when several modules were mounted under one cooler, was made. Results are shown in Fig. 13.

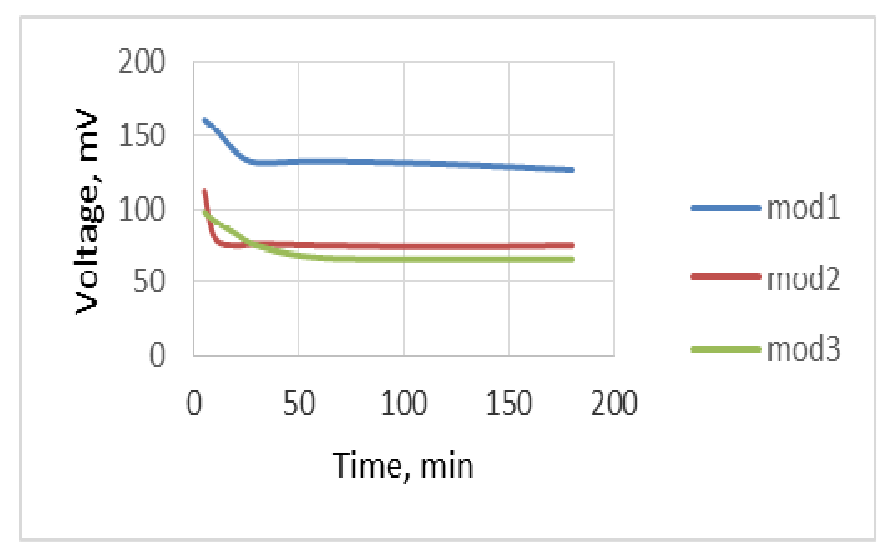

Fig. 13. Power of thermoelectric module in case when additional cooler is used and several modules are mounted, surface temperature is $50^{\circ} \mathrm{C}$.

We can see, that mounting several modules under one cooling element leads to the fall of performance. It means modules should be mounted with some intervals to provide better heat exchange.

\section{DISCUSSIONS}

Japanese researcher Kazuja Murakami has proposed to use thermoelectric modules for recovery of low potential heat from the surface of power transformers for electricity production [5].

A series of experiments, performed during the research, has shown that temperature difference between thermoelectric module hot and cold side is lower, than it was suggested in theoretical calculation. 
Transformer surface temperatures of 40 to $50{ }^{\circ} \mathrm{C}$, which are typical conditions for power transformers in Latvia, are not high enough to ensure proper work of thermoelectric generators. Our try to use thermoelectric cooler in "reverse" mode did not solve problem related with relatively low surface temperature.

Even with additional cooling fin, the temperature difference between the hot and cold side of the module was three times lower than theoretically acceptable. This adversely affected the performance of all tested thermoelectric modules.

Experiments with thermoelectric modules have also indicated that the performance of modules is better at higher temperatures, which could have a negative impact on transformers operation. This statement is consistent with the theory. At higher temperatures modules are able to use a larger amount of heat efficiently. Still, extra cooling could ensure the greater temperature difference between the hot and cold side of the module.

Thermoelectric modules are manufactured from different materials. And it is extremely difficult to find a high-quality and relatively cheap modules in the market. For example Ferrotec thermoelectric module, used in theoretical calculation, costs 70-100 EUR. Also there are problems with delivery to Europe. This is an additional negative factor for the wider use of modules.

The performance of thermoelectric modules is highly dependent on ambient temperature, temperature of hot surface and different factors which can affect the efficiency of cooling, such as sun, wind, rain. That makes hard to calculate real performance of thermoelectric module.

Experiments were made using stand alone thermoelectric module and several modules mounted one by other under one cooler. If more modules will be mounted close one to another that will affect heat exchange, so thermoelectric module efficiency can fall.

\section{CONCLUSIONS}

Main advantages of thermoelectric modules are those sizes, reliability and no moving parts used. But they all are outweighed by very low efficiency. They can harvest waste heat and produce electricity, but if other source of electricity is available, thermoelectric module becomes cost ineffective.

To gain higher performance of thermoelectric module, additional cooling should be provided. It means additional constructions will be mounted on power transformer surface, also it is additional costs. Which is technically complicated operation. Also, IEC and other standards should be taken into account. Which mean additional difficulties for thermoelectric module usage on power transformer surface.

Calculations and experiments performed in this research let us to conclude that usage of thermoelectric modules for recovery of low-potential heat from a surface of power transformers is not suitable in Latvian conditions. Even if we could obtain theoretical $259 \mathrm{~mW}$ from one module, and price of one module is 10 EUR. Installation of enough modules to produce one kilowatt will cost 38610 EUR, which is not economically viable.
In substations we can easily find much cheaper source of electricity. But this technology could be effectively applied to run measurement devices, which are far from electricity network, and high temperature heat source is available.

\section{REFERENCES}

[1] Иванов В. В., Соловьев Г. И. Электротехника. Учебное пособие. 6е изд., стер. Санкт-Петербург: Издательство «Лань», 2009 - 496 стр.

[2] А. Б. Богданов. Обзор шести передовых энергосберегающих технологий в электросетевом комплексе России // Электронный журнал Энергосвет. 2010. № 8. - стр. 60-64.

[3] Thermoelectric Technical Reference - Power Generation [Online]. Awailable: http://thermal.ferrotec.com/technology/thermoelectric/thermalRef13

[4] G.J. Snyder Small thermoelectric generators.

[5] K. Murakami, K. Sasaki, T. Schindoh, Y. Itoh. Development of waste heat recovery system from transformer with $\mathrm{Bi}-\mathrm{Te}$ thermoelectric modules.

[6] Moffat, R., Notes on Using Thermocouples, ElectronicsCooling. 1997, Vol. 3, No. 1.

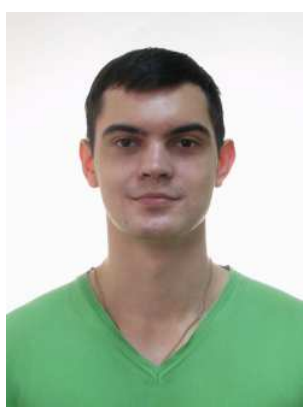

Roman Olekshii was born in Riga, Latvia on January 27, 1990. He received Dipl. BSc and M.Sc degree from Riga Technical University in 2012 and 2014 respectively.

After graduation from Riga Technical university in $2014 \mathrm{Mr}$. Olekshii has started his career in Latvian national power utility AS Latvenergo as CHPP technical information Technician.

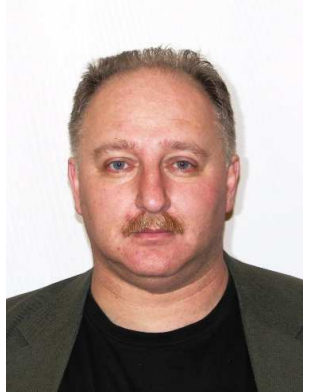

Nikolajs Kukḷa was born in Riga Latvia on October 21, 1962. He received Dipl. Eng., M.Sc and $\mathrm{PhD}$ degree from Riga Technical University in 1994, 1996 and 2008 respectively.

After graduation from Riga Technical university in 1984 Mr. Kukḷa has started to work in Latvian national power utility AS Latvenergo , High Voltage Network. He worked in high voltage laboratory as measurement specialist of 6-330 kV equipment. From 1985 till 1986

Mr. Kukḷa worked in Company ,Dalnije Elektroperedachi" and dialled with project 750 $\mathrm{kV}$ line from Ignalina Nuclear Power Stationsubstation Latvia. From 1986 Nikolajs Kukḷa still work in Latvian national power utility AS Latvenergo, Latvian Electricity Network in substation department.

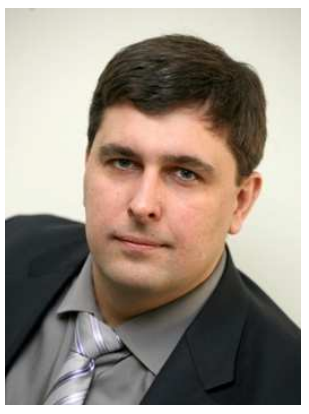

Olegs Linkevics was born in Jurmala, Latvia on December 27, 1973. He received Dipl. Eng., M.Sc and $\mathrm{PhD}$ degree from Riga Technical University in 1994, 1996 and 2008 respectively.

Since 2009, he is a Docent at Faculty of Electrical and Power engineering. He is teaching the introductory course "Basics of Electric and Heat Engineering" to the first year students in the Faculty of Electrical Engineering. Dr. Linkevics is participating in the scientific research work and supervising several students thesis for their bachelor and master degrees. In 2010 Olegs Linkevics was elected for the Associated Professor position.

After graduation from Riga Technical university in $1995 \mathrm{Mr}$. Linkevics has started his career in Latvian national power utility AS Latvenergo. For 19 years of working experience in the company he has grown up from the Planning Engineer to the Head of Development in the Research \& Development department. Mr. Linkevics main competence is preparation of development programs and strategies, research and feasibility studies. 